\title{
Computer card morphometry of jejunal biopsies in childhood coeliac disease
}

\author{
E. A. MEINHARD, D. G. WADBROOK, AND R. A. RISDON
}

From the Royal Free Hospital and The Hospital for Sick Children, London

SYNOPSIS The histological changes in 95 jejunal biopsy specimens from children have been analysed by a new morphometric technique. The microscope image of the specimen is traced directly onto computer data cards. A simple sketch records accurate quantitative data in a matrix of 840 points, retaining the spatial arrangement of the tissue components. The data are fed, via an optical mark data card reader, into a mini-computer. FORTRAN IV programs allow calculation of surface area, villous heights, and component volumes in metric units, and of volume proportions, volume-tovolume ratios, and surface-to-volume ratios. Pictorial and numerical printouts are produced, which are suitable for inclusion in the patient's notes.

Jejunal biopsies from 37 controls and 26 untreated coeliac patients were clearly distinguished morphometrically. Sixteen pairs of biopsies from coeliac patients on long-term gluten-free diets before, and 12 weeks after, the reintroduction of dietary gluten significantly reflected the effects of gluten challenge. Comparison of control and abnormal biopsies showed a spatial redistribution of the components, more than a change in their absolute amounts. There was no significant differences in the total epithelial volumes in controls, treated or untreated patients, suggesting that the mucosal lesion in coeliac disease is not a true atrophy.

The appearance of the jejunal mucosa in severe untreated coeliac disease differs greatly from the normal. However, between these two poles lies a range of different merging degrees of abnormality, which are grouped together, at present, as 'partial villous atrophy'. Descriptive qualitative observations do not suffice for accurate assessment and comparison of biopsies from individuals, groups, and treatment centres. Qualitative methods are required.

Numerous descriptive and quantitative studies have shown that the jejunal mucosa in coeliac disease is thickened compared with the normal, with fewer, thicker villi, larger crypts, a diminished ratio between the volume of surface epithelium and crypts, a smaller surface area, a reduced surface/volume ratio, and shorter surface cells (Doniach and Shiner, 1957; Shiner and Doniach, 1960; Rubin, Brandborg, Phelps, Taylor, Murray, Stemler, Howry, and Volwiler, 1960; Thurlbeck, Benson, and Dudley, 1960; Magdanopalan, Shiner, and Rowe, 1965; Stewart, Pollock, Hoffbrand, Mollin, and Booth, 1967; Dunnill and Whitehead, 1972; Chapman, Henry, Paice, Stewart, and Coghill, 1973). These

Received for publication 14 November 1974. methods have recently been reviewed by Dunnill and Whitehead (1972) and by Chapman et al (1973).

The biopsy appearances improve after the withdrawal of gluten and deteriorate again if gluten is returned to the diet (Anderson, 1960; Meeuwisse, 1970; Pollock, Nagle, Jeejeebhoy, and Coghill, 1970).

We report the application of a new morphometric technique (Meinhard, 1974) to single and serial jejunal biopsies in children. The microscope image of the biopsy specimen is sketched rapidly upon computer cards to produce calibrated, encoded morphometric data for direct computer analysis. Because the spatial arrangement of the data is preserved as a matrix, a large number of measurements, including all those mentioned above, can be made in the computer.

\section{The Patients}

We studied 95 jejunal biopsies from 79 children. Thirty-seven biopsies were taken from children under investigation for short stature or failure to thrive. Since none had investigational evidence of malabsorption, and all biopsies were subjectively 
normal, these specimens were regarded as controls. Twenty-six biopsies were taken from children with clinically typical coeliac disease before treatment. Thirty-two specimens were paired biopsies from 16 children with suspected coeliac disease, taken before, and some 12 weeks after the reintroduction of dietary gluten, following at least two years of an empirical gluten-free diet.

The age distribution of controls and untreated coeliacs was similar, with a range from 6 months to 14 years. The treated cases were from 4 to 13 years old.

All biopsies were taken perorally under fluoroscopic control, using a Crosby capsule, from a standard site just beyond the ligament of Treitz. The specimens were all similarly processed, and correctly orientated and embedded in paraffin wax under a large hand lens (Risdon and Keeling, 1974). The measurements refer to the processed biopsy, and are not corrected for shrinkage. The drawings were made without knowledge of the clinical findings.

\section{Method}

\section{THE DRAWINGS}

Eighty column computer data cards are printed in non-readable ink. The first 10 columns are for patient and component identification; the remaining card space is a grid of 70 vertical and 12 horizontal lines, which cross at the centre of the punch positions. These centred crosses form a matrix of 840 sampling points.

Each drawing is done on two superimposed data cards. An upper master card, which is fully punched from columns 11 to 80 , forms a template over a lower component card. The cards are placed beneath the drawing attachment of a microscope (fig 1) and calibrated by obtaining the coincidence of any two grid lines with any two lines on a stage micrometer gauge. A well aligned representative field of the jejunal biopsy slide (Risdon and Keeling, 1974) is positioned so that its image falls across the computer card grid. With a $\times 10$ objective, an approximately $1.75 \mathrm{~mm}$ length of the biopsy, transecting up to 12 villi, is quantitated.

Selected components of the biopsy are traced on the cards (figs 1, 2, 3), forming a sketch on the upper master card, and a series of marks on the lower component card where the cross points of the grid coincide with the component. The component card is thus equivalent to a point-counting graticule with 840 points, with the $x y$ coordinates (and thus the relative position) of each point known. For each new component, a new component card is slipped beneath the master card.

The component cards are read by an optical mark

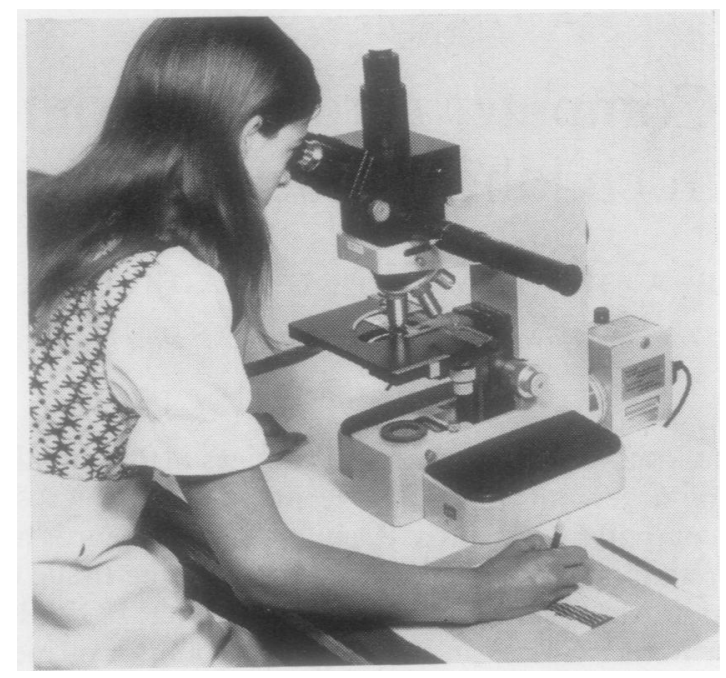

Fig 1 Worker completing a record. She can see the magnified image of the microscope specimen lying upon the image of the computer cards.

data card reader and the data transferred, via 12-line input, into a mini-computer.

INPUT DATA

In this study, four component cards were produced for each biopsy field (total drawing time is approxi- $\bigcirc$ mately 15 minutes per biopsy). They were:

\section{A 'Not mucosa' (figs $2 c, 3 c$ )}

Points falling above the mucosal surface, or upon the muscularis mucosa or submucosa. A total 횽 mucosa matrix was found by logically inverting each element in the 'not mucosa' array within the 3 . computer.

\section{B Jejunal surface epithelium ( $f$ igs $2 d, 3 d$ )}

\section{Crypt epithelium (figs $2 e, 3 e$ )}

D Vertical lines from the top to the base of each villus (figs $2 f, 3 f$ )

The cumulative villus height per drawing is obtained by summing the lengths of the vertical lines. The lower ends of these lines are used to delineate $a$ boundary between the upper, villus-related, and the lower, crypt-related areas of the $70 \times 12$ matrix. $\stackrel{\mathbb{\Phi}}{+}$ Where there are no villi, the marks delineate the surface.

DATA PROCESSING reader in binary image form (ie, as an array of $1 \mathrm{~s}$ and $0 \mathrm{~s})$, to a computer program designed to produce 


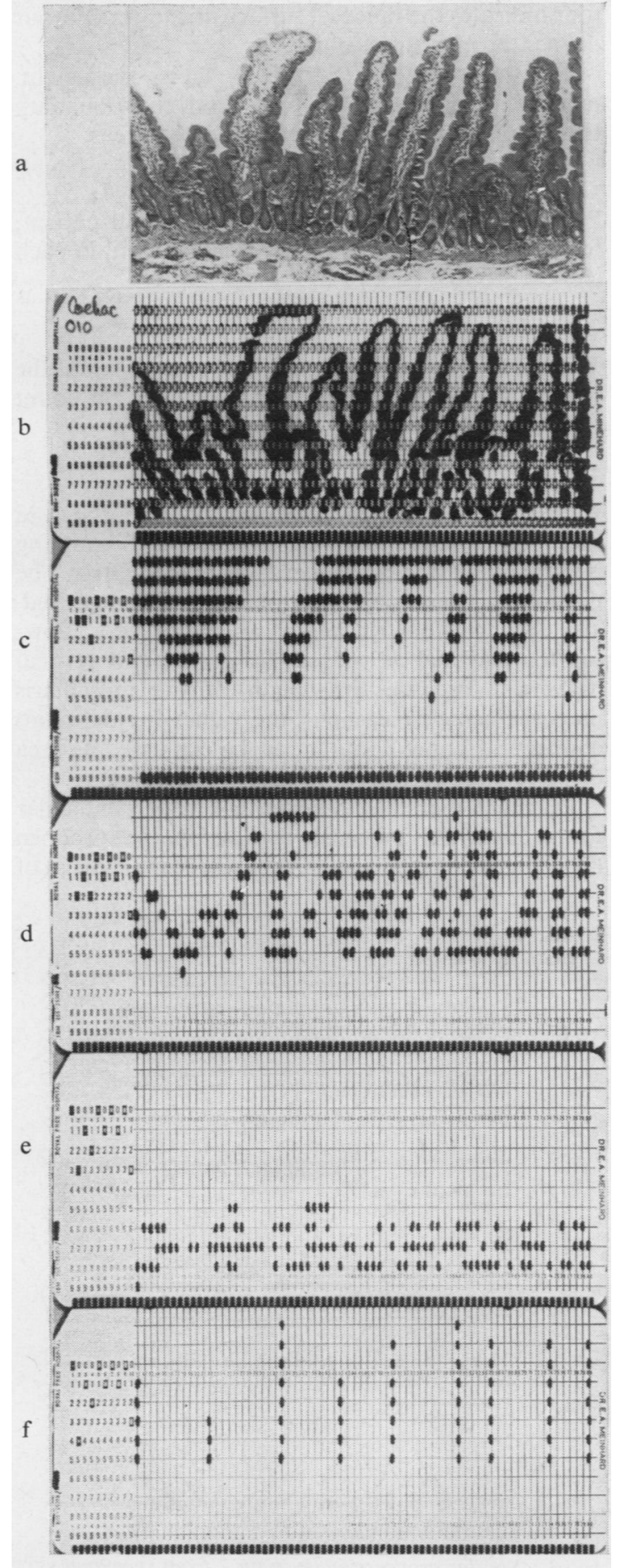

both pictorial and numerical outputs in a format suitable for inclusion in the patient's notes (Wadbrook and Meinhard, in preparation).

\section{PICTORIAL REPRESENTATION}

Three diagrams are produced by the computer. These contain in pictorial form all the information used in the numerical procedure. The first diagram (figs $2 \mathrm{~g}, 3 \mathrm{~g}$ ) identifies points in the field as being surface epithelium (V), crypt epithelium (K), or lamina propria $(\mathrm{L})$. The lamina propria is obtained by subtracting surface and crypt epithelium components from the total mucosa matrix and does not have to be directly quantitated.

The second diagram (figs $2 \mathrm{~h}, 3 \mathrm{~h}$ ) shows the results of the computer performing a contour extraction process on the total mucosa matrix. The upper con-

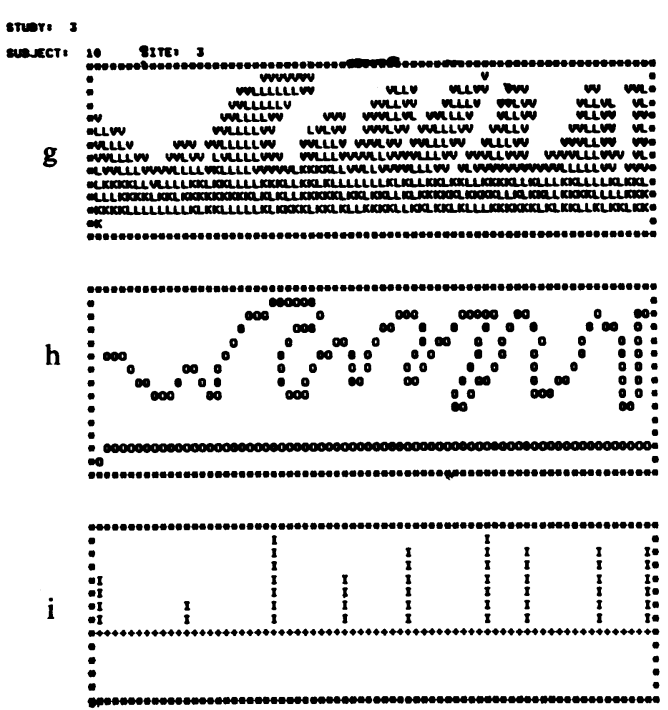

Fig 2 The progression from specimen via coded computer cards to computer pictorial printout:

a Photomicrograph of a control biopsy $(H \& E \times 50)$

b The master card

c 'Not mucosa' component card

d Surface epithelium component card

e Crypt component card

f Villous height, position, and number component card

\& Computer printout of map of mucosal components

$$
\begin{aligned}
& \mathbf{V}=\text { surface epithelium } \\
& \mathbf{K}=\text { crypt } \\
& \mathbf{L}=\text { lamina propria }
\end{aligned}
$$

$\mathrm{h}$ Computer printout of contour extraction showing surface above and muscularis mucosae below

i Computer printout showing height, position, and number of villi, and boundary between villus-related and crypt-related areas of mucosa 


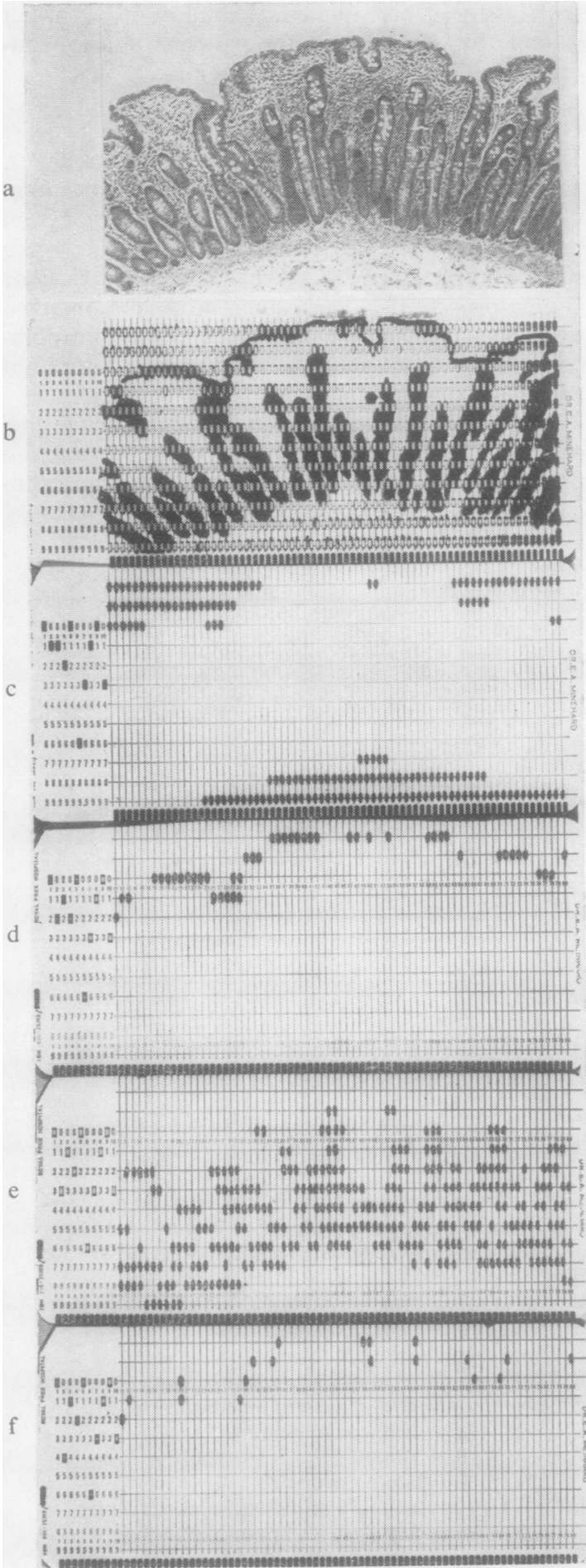

tour indicates the mucosal surface, the lower contour defines the muscularis mucosae.

The third diagram (figs $2 \mathrm{i}, 3 \mathrm{i}$ ) shows the height, number, and site of the villi, and the boundary between villus-related and crypt-related areas.

THE NUMERICAL COMPUTATION (FIGS 4, 5) Printouts are produced for each individual patient, for means, and for standard deviations within each clinical group.

\section{Volume proportions}

The volume proportions are computed from the point-counts of each component related to the count of the total mucosa.

\section{Measurements}

Calibration defines the distance between the grid lines. Hence an area can be assigned to each sampling point, and to each component within the matrix. The distance between any two points can be measured. The distance along a contour can be summed, allowing for diagonal as well as horizontal and vertical 'traverse'. Because the length of the muscularis mucosae can be measured, the values for the point counts and upper contour can be expressed as area or perimeter per $1 \mathrm{~mm}$ muscularis mucosae.

Provided that the specimen is cut perpendicular to the muscularis mucosae, the microscope specimen (fig 6) may be taken as a sample test plane, typical of

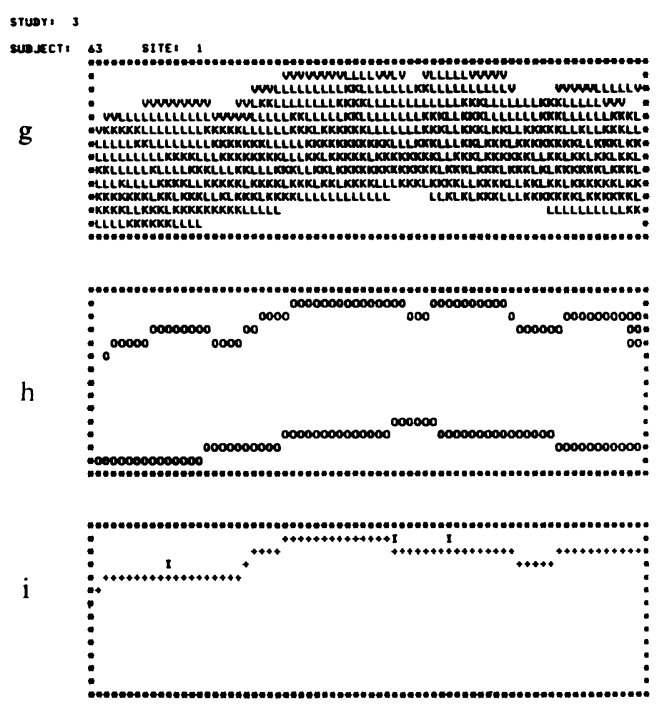

Fig 3 Similar progression as in fig 2 from specimen via coded computer cards, to computer pictorial printout, in a biopsy from a child with untreated coeliac disease. 
susect 10 SITE 3

rolnt coumts

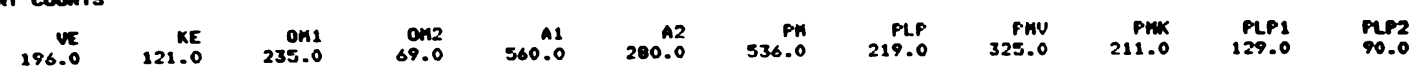

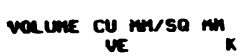

$$
\underset{\text { UE }}{.188}
$$

KE

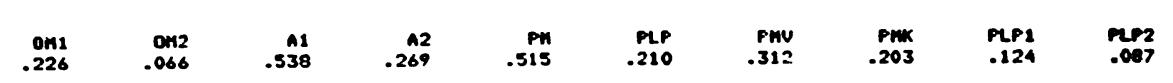

voe une Froportiows

$\begin{array}{lllllll}\text { XVE } & \text { XKE } & \text { XLF } & \text { XLF1 } & \text { XLP2 } & \text { XLL1 } & \text { XLL2 } \\ .366 & .226 & .409 & .241 & .168 & .589 & .411\end{array}$

RATIOS

\begin{tabular}{|c|c|c|c|c|c|c|}
\hline $\begin{array}{r}\text { V/K } \\
1.620\end{array}$ & $\begin{array}{l}\text { V/LF } \\
.895\end{array}$ & $\begin{array}{r}\text { U/LV } \\
1.519\end{array}$ & תT & $\begin{array}{l}\text { K/LF } \\
.553\end{array}$ & $\begin{array}{l}\text { K/LK } \\
1.344\end{array}$ & $\begin{array}{l}\text { LV/LK } \\
1.433\end{array}$ \\
\hline
\end{tabular}

UPFER LEMGTH $=7.000$ LOUER LENGTH $=1.800$

SURFACE RATIO = 3.933

SUPFACE/TOTAL MUCOSA $=7.635$

SURFACE/VILLUS VOLUME $=20.880$

SUEGACE/KRYPT volune $=33.822$

COMRATIVE UILLUS HEIGHT $=3360.0$ UH

Fig 4 Computer numerical printout of the control

muser of UILLI $=9.0$

biopsy shown in figure 2.

UPFER LEMGTH $=2.340 \quad$ LOMER LEMGTH $=2.12 \mathrm{C}$

SUFACE RATIO $=1.104$

SUPAACE/TOTAL MUCOSA $=2.034$

suaface/UILLUS volune $=27.604$

SUAFACE/KRYPT WOLUnE $=\$ .420$

COMLATIUE UILLUS HEIGHT $=210.0 \mathrm{UH}$

MUEer of VILLI = 3.0

Fig 5 Computer numerical printout of the untreated coeliac biopsy shown in figure 3. 


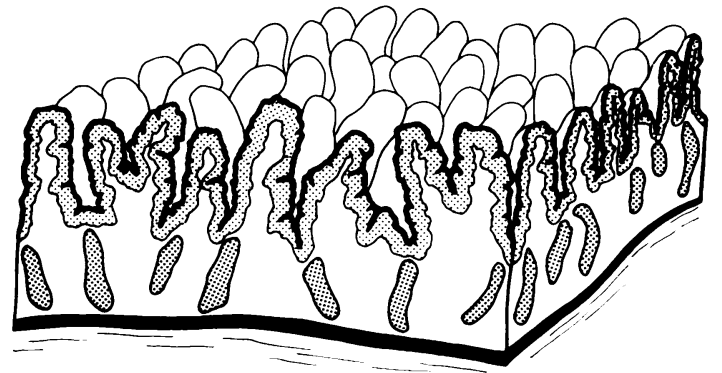

Fig 6 Diagrammatic representation of the quantitated biopsy to show that a section perpendicular to the muscularis mucosae may be taken as a sample test plane typical of findings at any depth in the block and at any orientation. Thus measurements of the two-dimensional microscope section can be used to estimate threedimensional quantities. We have related our measurements to the mucosa sitting upon one square millimetre of muscularis mucosae.

findings at any depth in the block, at any orientation. Three-dimensional randomness of structure is not necessary in this method. Just as volumes of components may be found from their two-dimensional areas in a typical transection (Delesse, 1848), so the surface area may also be found from the measured two-dimensional contour lengths. The volumes and surface areas can be expressed in absolute terms, related to the amount of mucosa sitting upon 1 square millimetre of muscularis mucosae.

Once the basic numerical data are computed, volume/volume and surface/volume ratios may be found for any items.

\section{REPEATABILITY}

Duplicate drawings were done of the same and different fields, of up to five different levels through the biopsy, with different stains, microscopes, magnification, and observers. Only one biopsy result showed an inter-observer discrepancy; here the comparison of master cards as 'quality control' revealed differing decision criteria. Subjective decisions of boundary between villus and crypt, although occasionally difficult, appeared less arbitrary than has been suggested (Dunnill and Whitehead, 1972).

\section{Results}

Individual pictorial and numerical computer printouts are produced for each biopsy (figs 2, 3, 4, and 5). Numerical printouts are also produced of the means and standard deviations within each of the four clinical groups-controls, treated gluten-free coeliacs, treated coeliacs given a gluten challenge, and untreated coeliacs. These results are summarized in the table.

\begin{tabular}{|c|c|c|c|c|c|c|c|c|}
\hline & \multirow{2}{*}{\multicolumn{2}{|c|}{ Controls }} & \multicolumn{4}{|c|}{ Treated Coeliacs } & \multirow{2}{*}{\multicolumn{2}{|c|}{ Untreated Coeliacs }} \\
\hline & & & \multicolumn{2}{|c|}{ Gluten-free } & \multicolumn{2}{|c|}{ Gluten Challenge } & & \\
\hline & \multicolumn{2}{|c|}{ Mean $\pm S D$} & \multicolumn{2}{|c|}{ Mean $\therefore S D$} & \multicolumn{2}{|c|}{ Mean $=S D$} & \multicolumn{2}{|c|}{ Mean $\div S D$} \\
\hline \multicolumn{9}{|l|}{ Volume $\left(\mathrm{mm}^{3} / \mathrm{mm}^{2}\right.$ muscularis mucosae $)$} \\
\hline Total mucosa & 0.45 & 0.07 & 0.46 & 0.09 & 0.42 & 0.07 & 0.43 & 0.07 \\
\hline Epithelium Surface & $0 \cdot 16$ & 0.04 & 0.15 & 0.04 & 0.05 & 0.02 & 0.03 & 0.01 \\
\hline Crypt & 0.09 & 0.03 & $0 \cdot 10$ & 0.03 & $0 \cdot 15$ & 0.04 & 0.17 & 0.04 \\
\hline Total & $0 \cdot 25$ & & $0 \cdot 25$ & & $0 \cdot 20$ & & $0 \cdot 20$ & \\
\hline Lamina propria Surface related & $0 \cdot 11$ & 0.03 & $0 \cdot 11$ & 0.04 & 0.06 & 0.03 & 0.03 & 0.01 \\
\hline Crypt related & 0.09 & 0.03 & 0.11 & 0.04 & $0 \cdot 16$ & 0.04 & 0.20 & 0.04 \\
\hline Total & $0 \cdot 20$ & 0.03 & $0 \cdot 22$ & 0.06 & $0 \cdot 22$ & 0.04 & $0 \cdot 23$ & $4 \cdot 04$ \\
\hline \multicolumn{9}{|l|}{ Mucosal volume proportions (\%) } \\
\hline Surface epithelium & 34 & 6 & 31 & 7 & 13 & 6 & 8 & 2 \\
\hline Crypts & 21 & 5 & 22 & 4 & 35 & 6 & 39 & 6 \\
\hline Lamina propria Total & 45 & 5 & 47 & 5 & 52 & 4 & 53 & 6 \\
\hline Crypt related & 20 & 6 & 22 & 7 & 39 & 8 & 47 & 5 \\
\hline Villus-related/crypt-related lamina propria & 1.74 & 0.59 & 1.53 & 0.56 & $0 \cdot 39$ & $0 \cdot 23$ & 0.21 & 0.08 \\
\hline Crypt-related/total lamina propria & $\begin{array}{l}1 \cdot 34 \\
0.47\end{array}$ & $\begin{array}{l}0 \cdot 67 \\
0 \cdot 12\end{array}$ & $\begin{array}{l}1 \cdot 27 \\
0.47\end{array}$ & $\begin{array}{l}0 \cdot 72 \\
0 \cdot 11\end{array}$ & $\begin{array}{l}0.41 \\
0 \cdot 66\end{array}$ & $\begin{array}{l}0 \cdot 29 \\
0 \cdot 14\end{array}$ & $\begin{array}{l}0.15 \\
0.74\end{array}$ & $\begin{array}{l}0.05 \\
0 \cdot 19\end{array}$ \\
\hline $\begin{array}{l}\text { Surface area }\left(\mathrm{mm}^{2} / \mathrm{mm}^{2} \text { muscularis mucosae }\right) \\
\text { Surface/Volume ratio }\end{array}$ & $3 \cdot 13$ & $0 \cdot 81$ & $2 \cdot 70$ & $0 \cdot 96$ & $1 \cdot 39$ & $0 \cdot 34$ & $1 \cdot 13$ & $0 \cdot 13$ \\
\hline Surface/total mucosa & $7 \cdot 0$ & 1.6 & $5 \cdot 8$ & $1 \cdot 8$ & $3 \cdot 3$ & 0.9 & $2 \cdot 7$ & 0.5 \\
\hline Surface/surface epithelial volume & $20 \cdot 7$ & $4 \cdot 3$ & $18 \cdot 6$ & $3 \cdot 8$ & $29 \cdot 8$ & $9 \cdot 8$ & $36 \cdot 5$ & $10 \cdot 0$ \\
\hline Surface/crypt volume & $35 \cdot 5$ & 13.5 & 28.6 & $13 \cdot 6$ & $10 \cdot 1$ & $4 \cdot 1$ & $7 \cdot 2$ & $2 \cdot 1$ \\
\hline Number of villi & 11 & 2 & 10 & 2 & 4 & 4 & $0 \cdot 5$ & 1 \\
\hline Cumulative villous height $(\mu)$ & 2942 & 142 & 2634 & 898 & 508 & 511 & $50 \cdot 4$ & 98 \\
\hline Thickness of mucosa (minus villi) $(\mu)$ & 201 & 42 & 219 & 61 & 352 & 81 & 431 & 78 \\
\hline $\begin{array}{l}\text { Height of surface cells (derived from surface } \\
\text { epithelial volume/surface area) }(\mu)\end{array}$ & 49 & & 53 & & 37 & & 29 & \\
\hline
\end{tabular}

Table Results of grouped data 


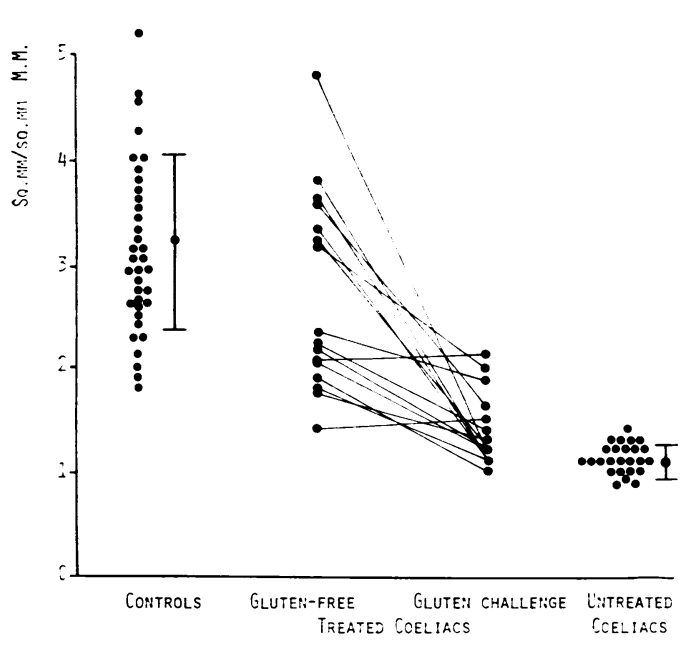

Fig 7 The surface area of controls, treated, and untreated coeliacs. Lines join the paired results of biopsies from individual treated coeliacs, taken before and after gluten challenge. The deleterious effect of gluten is clearly shown.

There are numerous significant differences between the results from controls and untreated coeliacs.

Untreated coeliac mucosae are indeed 'flat', for the surface area falls from a control value of $3.13 \mathrm{~mm}^{2} / \mathrm{mm}^{2}$ muscularis mucosae to $1 \cdot 13 \mathrm{~mm}^{2} / \mathrm{mm}^{2}$ muscularis mucosae (fig 7). The surface epithelial volume falls (fig 8) from $0.16 \mathrm{~mm}^{3} / \mathrm{mm}^{2}$ muscularis mucosae (or $34 \%$ of total mucosal volume) to 0.03

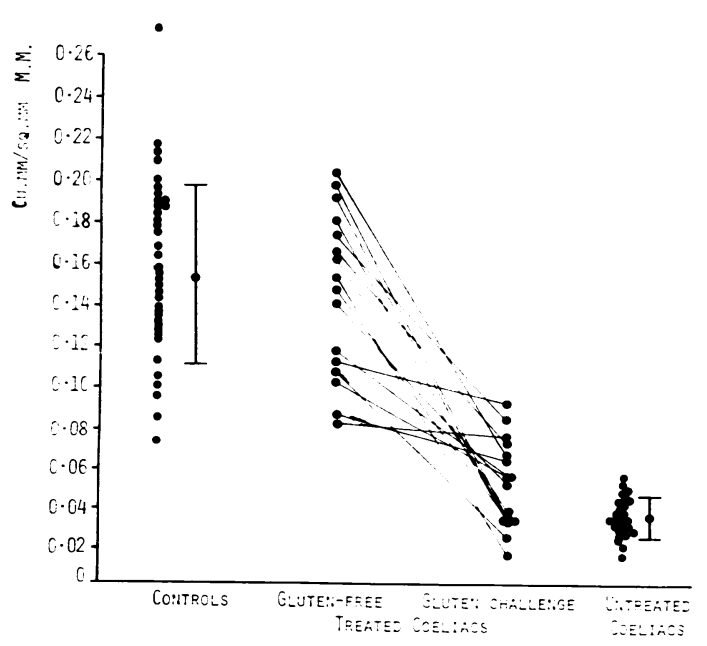

Fig 8 The volume of the surface epithelium of controls and treated and untreated coeliacs. $\mathrm{mm}^{3} / \mathrm{mm}^{2}$ muscularis mucosae (or a mere $8 \%$ of total mucosal volume). The cumulative villus height per drawing falls similarly from $2942 \mu$ to $50 \mu$.

The crypt volume rises significantly in untreated coeliac mucosa from control volume of $0.09 \mathrm{~mm}^{3} / \mathrm{mm}^{2}$ muscularis mucosae $(21 \%$ of total mucosal volume) to $0.17 \mathrm{~mm}^{3} / \mathrm{mm}^{2}$ muscularis mucosae (or $39 \%$ of total mucosal volume).

The ratio of surface epithelial volume to crypt volume falls significantly from 1.74 in controls to 0.21 in untreated coeliacs. The volumes of surface-related and crypt-related lamina propria show a pattern of changes similar to their respective epithelial components.

When on a gluten-free diet, the treated coeliac

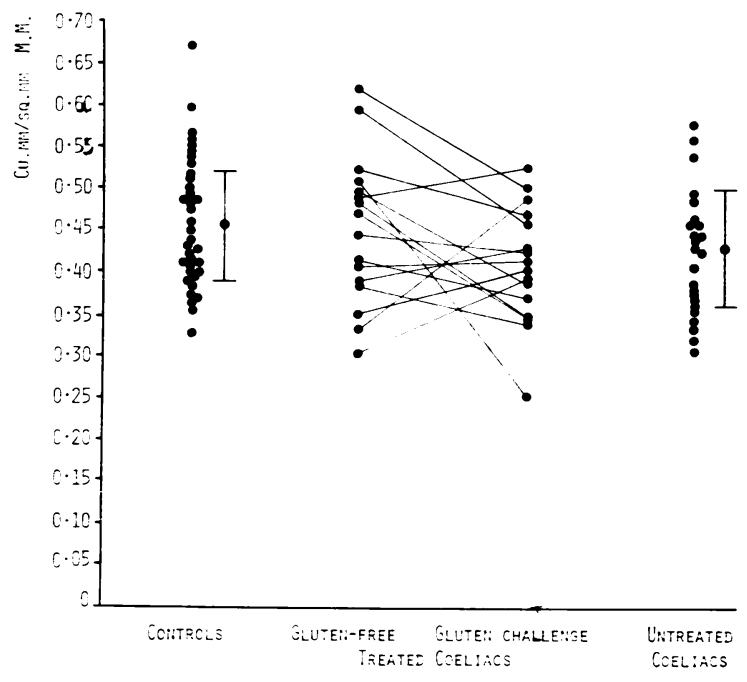

Fig 9 The total mucosal volume of controls and treated and untreated coeliacs. There is no statistical difference between the four groups.

children show few differences from the controls. A return of dietary gluten causes a reversion of the results towards those of the untreated coeliac group (figs 7 and 8).

However, the total mucosal volume does not differ between the four groups (fig 9). The distribution of results is the same and the mean mucosal volume is almost identical in all four groups (comparing controls and untreated coeliacs, Student's $t=1 \cdot 19$, $P>0 \cdot 2$. A paired $t$ test shows no significant difference between the pre- and post-gluten challenge biopsies of the treated coeliacs.)

\section{Discussion}

Current morphometric methods derive largely from 
mineralogy and metallurgy (Weibel, 1962; DeHoff and Rhines, 1968) with theoretical bases in geometric probabilities of structures randomly orientated in three dimensions. However, animate tissues are rarely arranged randomly, still less the processes of disease. The site, orientation, and magnification of the microscope specimen and method of sampling must be chosen so as to reveal the structures in the most meaningful way. Comparison between specimens demands comparable preparation.

Computer card morphometry is a modification of point counting (Glagolev, 1933). The collection of data is just as simple, at least as rapid, and more easily checked, compared with current morphometric methods (Freere and Weibel, 1967; Dunnill, 1968), yet the data, once collected, are in a more valuable, adaptable form, already coded for computation and analysis. Retention of the spatial arrangement of the point count decisions as a coded matrix allows, in effect, a reconstruction of a measured image within the computer. Three-dimensional quantities can be estimated from measurements made upon twodimensional samples. Because the matrix is calibrated, components can be quantified in absolute values, as well as in proportional terms. Pictorial and numerical printouts of the measured biopsies can be produced, which are suitable for inclusion in the patient's notes.

The master card speeds the process of quantitation (which takes about 15 minutes) and later forms a useful visual record. Master cards of all biopsies can be viewed and reviewed simultaneously.

The results are reproducible at various levels in a single biopsy and are similar within each clinical group, even though the biopsy and area quantitated are small.

Three of our measurements-surface area, surface epithelial volume, and cumulative villous heightare functions of surface complexity. There was overall agreement of results from these three measurements, which are obtained by differing independent operations. The villous height measurements are taken from the random plane of section, which cuts through the slope more often than the apex of the villus (compare Underwood, 1968, on sizing of spheres). Thus, in our controls, the mean cumulative villous height for 11 villi is $2942 \mu$ which would give an expectedly lower mean villus height $(276 \mu)$ than the 370-540 $\mu$ quoted by Doniach and Shiner (1957), who measured only full villi.

This study measured 95 jejunal biopsies from children in four clinical states; 37 controls, 25 untreated coeliacs, and 16 treated coeliacs who were biopsied while taking a gluten-free diet and rebiopsied 12 weeks after reintroduction of dietary gluten.
There are many significant differences in the data from controls and from children with untreated coeliac disease. The abnormal biopsies show a fall in surface area (fig 7); a decrease in height and number of the villi; a fall in surface epithelial volume (fig 8); a fall in height of surface cells; an increased crypt volume; and an increase in mucosal thickness compared with controls.

The volume of surface epithelium falls markedly, because not only does the surface area decrease to one third of the control value, but also the surface cell height is reduced. As surface epithelial volume falls and crypt volume rises, the ratio of surface epithelial volume to crypt volume falls dramatically in coeliac disease (Chapman et al, 1973). There is a similar fall in the volume ratio of villus-related and crypt-related lamina propria. The surface/volume ratio is significantly lower in coeliac disease (Dunnill and Whitehead, 1972) but gives no better separation of groups than surface area alone, because the mean mucosal volume of the different groups does not vary.

Quantitation of serial biopsies in coeliac individuals reflects the effects of gluten challenge (figs 7 and 8), useful diagnostically and for monitoring of progress (Pollock et al, 1970; Meeuwisse, 1970; Anderson, Gracey, and Burke, 1972). Sixteen children with suspected coeliac disease had been treated empirically by gluten-free diet for at least two years. The morphometric data for these treated gluten-free coeliacs is similar to the controls. This suggests that dietary exclusion of gluten heals the lesion, at least in children (Anderson, 1960; Pollock et al, 1970).

With the reintroduction of gluten, the various components revert towards the untreated state, demonstrating the deleterious effect of gluten. Fourteen patients had adhered strictly to their glutenfree diet. The two patients who had broken their diet showed low surface area and surface epithelial volume in the first biopsy and little change after gluten challenge.

In both untreated coeliacs and treated coeliacs given a gluten challenge, the marked fall in surface epithelial volume is associated with a rise in crypt volume (fig 10). This alteration in the distribution of the epithelium is in keeping with the known increase in exfoliation of surface cells, increased mitotic rate, and upward migration of crypt cells and increased enzyme activity within crypts at a site free from gluten damage (Creamer, 1967, Croft, Loehry, and Creamer, 1968; Trier and Browning, 1970; Morson and Dawson, 1972). The mean lamina propria volume increases only slightly (from 0.20 to 0.23 $\mathrm{mm}^{3} / \mathrm{mm}^{2}$ muscularis mucosae) despite the obvious increase in number of inflammatory cells (fig 10). 


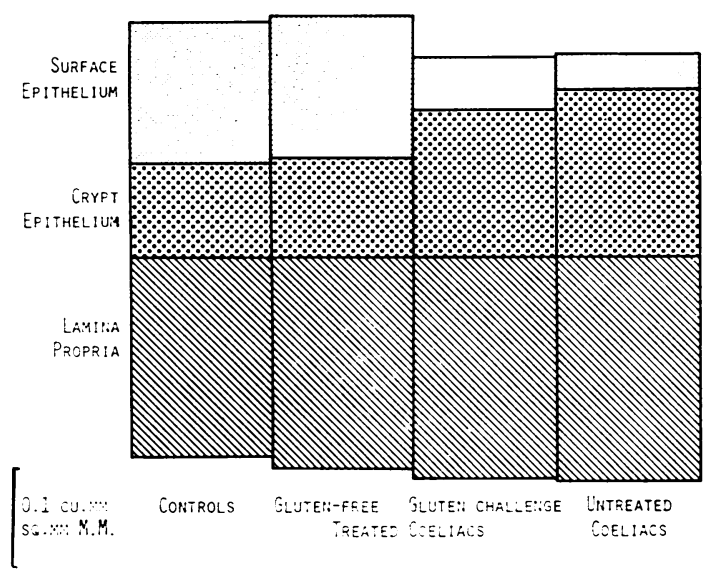

Fig 10 The mean volumes of total mucosa, epithelium, and lamina propria, in controls, treated coeliacs before and after gluten challenge, and untreated coeliacs. In coeliacs ingesting gluten, the fall in surface epithelial volume is associated with a rise in crypt volume. There is re-distribution of the components, but no true atrophy.

It is notable that the total mucosal volume does not differ significantly in the four groups studied (figs 9,10 ). There is a change in spatial distribution of components, more than a change in their absolute amounts. From this we conclude that there is no true mucosal atrophy in coeliac disease.

E.A.M. has received a project grant from the Medical Research Council for the purchase of equipment.

We thank Professor G. B. D. Scott for his kindly encouragement, J. Cox and Mr C. Gilson for help with the illustrations, and Miss Jill Vernon for the typescript.

\section{References}

Anderson, C. M. (1960). Histological changes in the duodenal mucosa in coeliac disease: reversibility during treatment with a wheat gluten free diet. Arch. Dis. Childh., 35, 419-427.

Anderson, C. M., Gracey, M., and Burke, V. (1972). Coeliac disease: some still controversial aspects. Arch. Dis. Childh., 47, 292-298.

Chapman, B. L., Henry, K., Paice, F., Stewart, J. S., and Coghill, N. F. (1973). A new technique for examining intestinal biopsies. Gut, 14, 905-909.

Creamer, B. (1967). The turnover of the epithelium of the small intestine. Brit. med. Bull., 23, 226-230.

Croft, D. N., Loehry, C. A., and Creamer, B. (1968). Small bowel cell loss and weight loss in the coeliac syndrome. Lancet, 2, 68-70.

DeHoff, R. T., and Rhines, F. N., eds. (1968). Quantitative Microscopy. McGraw-Hill, New York.

Delesse, A. (1848). Procédé méchanique pour déterminer la composition des roches. Annls. Mines, 13, 379-388.

Doniach, I., and Shiner, M. (1957). Duodenal and jejunal biopsies. II. Histology. Gastroenterology, 33, 71-86.

Dunnill, M. S. (1968). Quantitative methods in histology. In Recent Advances in Clinical Pathology, Series V, edited by S. C. Dykes, pp. 401-416. Churchill, London.

Dunnill, M. S., and Whitehead, R. (1972). A method for the quantitation of small intestinal biopsy specimens. J. clin. Path., 25, 243-246.

Freere, R. H., and Weibel, E. R. (1967). Sterological techniques in microscopy. J. roy. micr. Soc., 87, 25-34.

Glagolev, A. A. (1934). Quantitative analysis with the microscope by the 'point' method. Engng. Min. J., 135, 399-400.

Magdanopalan, N., Shiner, M., and Rowe, B. (1965). Measurements of small intestinal mucosa obtained by peroral biopsy. Amer. J. Med., 38, 42-53.

Meeuwisse, G. W. (1970). Diagnostic criteria in coeliac disease. (Report of discussion: European Society for Paediatric Gastroenterology). Acta paediat. scand., 59, 461-463.

Meinhard, E. A. (1974). Histoquantitation using computer data cards. J. Microscopy, 101, 95-102.

Morson, B. C., and Dawson, I. M. P. (1972). Gastrointestinal Pathology, pp. 308-310. Blackwell, Oxford.

Pollock, D. J., Nagle, R. E., Jeejeebhoy, K. N., and Coghill, N. F. (1970). The effect on jejunal mucosa of withdrawing and adding dietary gluten in cases of idiopathic steatorrhoea. Gut, 11. 567-575.

Risdon, R. A., and Keeling, J. W. (1974). Quantitation of the histological changes found in small intestinal biopsy specimens from children with suspected coeliac disease. Gut, 15, 9-18.

Rubin, C. E., Brandborg, L. L., Phelps, P. C., Taylor, H. C., Jr., Murray, C. V., Stemler, R., Howry, C., and Volwiler, W. (1960). Studies in celiac disease. Gastroenterology, 38, 517-535.

Shiner, M., and Doniach, I. (1960). Histopathological studies in steatorrhea. Gastroenterology. 38, 419-440.

Stewart, J. S., Pollock, D. J., Hoffbrand, A. V., Mollin, D. L., and Booth, C. C. (1967). A study of proximal and distal intestinal structure and absorptive function in idiopathic steatorrheoea, Ouart. J. Med., 36, 425-444.

Thurlbeck, W. M., Benson, J. A., Jr., and Dudley, H. R., Jr. (1960). The histopathologic changes of sprue and their significance. Amer. J. clin. Path., 34, 108-117.

Trier, J. S., and Browning, T. H. (1970). Epithelial-cell renewal in cultured duodenal biopsies in celiac sprue. New Engl. J. Med., 283, 1245-1250.

Underwood, E. E. (1968). Particle size distribution. In Quantitative Microscopy, edited by R. T. DeHoff and F. N. Rhines. McGraw-Hill, New York.

Wadbrook, D. G., and Meinhard, E. A. (In preparation).

Weibel, E. R. (1963). Morphometry of the Human Lung. Springer, Berlin. 